\title{
Postglacial climate changes and rise of three ecotypes of harbour porpoises, Phocoena phocoena, in western Palearctic waters
}

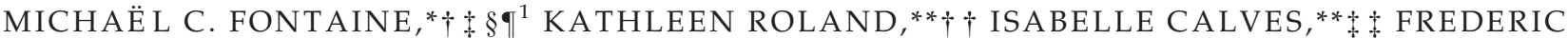

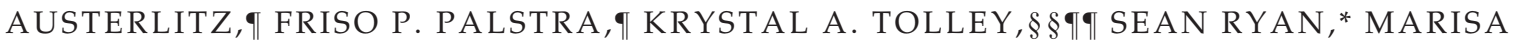

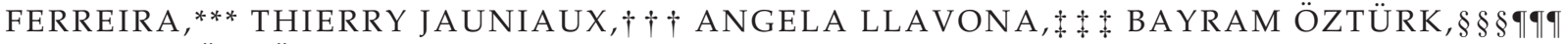

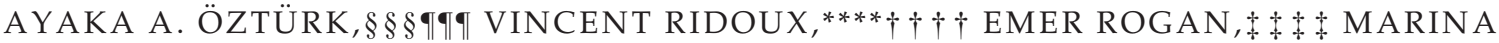 \\ SEQUEIRA, $\S \S \S$ URSULA SIEBERT, \\ BORRELL,$\dagger+\dagger \dagger \dagger$ JOHAN R. MICHAUX** and ALEX AGUILAR $\uparrow+\uparrow \dagger \dagger$ \\ *Department of Biological Sciences, University of Notre Dame, Notre Dame, IN 46556, USA, †Ecologie, Systématique et \\ Evolution, UMR8079, Université Paris-Sud, F-91405 Orsay, France, \$CNRS, 91405, Orsay, France, §AgroParisTech, F-91405 \\ Orsay, France, $\mid$ Eco-Anthropologie et Ethnobiologie, UMR 7206 CNRS, MNHN, Sorbonne Paris Cité, Université Paris Diderot, \\ F-75005 Paris, France, **INRA, UMR 1064 CBGP, Campus international de Baillarguet, CS30016, F-34988 Montferrier-sur-Lez \\ Cedex, France, $\dagger \dagger$ Research Unit in Environmental and Evolutionary Biology (URBE), Narilis (Namur Research Institute for \\ Lifesciences), University of Namur (FUNDP), Rue de Bruxelles 61, B-5000 Namur, Belgium, \$Laboratoire LEMAR (UMR \\ CNRS/UBO/IRD/Ifremer 6539), Institut Universitaire Européen de la Mer, Technopôle Brest-Iroise, Rue Dumont d'Urville, 29280 \\ Plouzané, France, §§Applied Biodiversity Research, South African National Biodiversity Institute, Private Bag X7, Claremont, \\ 7735 Cape Town, South Africa, $\uparrow \llbracket$ Department of Botany E Zoology, Stellenbosch University, Private Bag X1, Matieland, 7602 \\ South Africa, ${ }^{* * *}$ Departmento de Biologia, Sociedade Portuguesa de Vida Selvagem \& Molecular and Environmental Biology \\ Centre (CBMA), Universidade de Minho, Campus de Gualtar, 4710-047 Braga, Portugal, †††Department of Pathology, University \\ of Liège, Sart Tilman B43, 4000 Liège, Belgium, \$+†.E.M.MA. Coordinadora para o Estudio dos Mamíferos MAriños, Apartado \\ 15, 36380 Nigrán, Pontevedra, Spain, §§§Faculty of Fisheries, Istanbul University, Ordu Cad. No.200, 34320 Laleli-Istanbul,

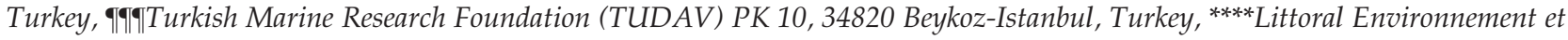 \\ Sociétés, UMR 7266, Université de La Rochelle/CNRS, F-17000 La Rochelle, France, ††††Observatoire PELAGIS - Systèmes \\ d'Observation pour la Conservation des Mammifères et des Oiseaux Marins, UMS 3462 Université de La Rochelle/CNRS, F-17000 \\ La Rochelle, France, $+4+\$$ School of Biological, Earth and Environmental Sciences, University College Cork, Cork, Ireland, \\ $\S \S \S \S$ Instituto da Conservação da Natureza e das Florestas, Rua de Santa Marta 55, 1169-230 Lisboa, Portugal, $19 \uparrow \uparrow \mid$ Institute for \\ Terrestrial and Aquatic Wildlife Research, University of Veterinary Medicine Hannover, Foundation, Werftstr. 6, 25761 Büsum, \\ Germany, ${ }^{* * * * *}$ Marine Research Institute, PO Box 1390, 121 Reykjavik, Iceland, $\dagger \dagger+\dagger \dagger$ Department of Animal Biology and IRBio, \\ Faculty of Biology, University of Barcelona, Diagonal 643, 08071 Barcelona, Spain,
}

\begin{abstract}
Despite no obvious barriers to gene flow in the marine realm, environmental variation and ecological specializations can lead to genetic differentiation in highly mobile predators. Here, we investigated the genetic structure of the harbour porpoise over the entire species distribution range in western Palearctic waters. Combined analyses of $\mathbf{1 0}$ microsatellite loci and a 5085 base-pair portion of the mitochondrial genome revealed the existence of three ecotypes, equally divergent at the mitochondrial genome, distributed in the Black Sea (BS), the European continental shelf waters, and a previously overlooked ecotype in the upwelling zones of Iberia and Mauritania. Historical demographic inferences using approximate Bayesian computation $(A B C)$ suggest that these
\end{abstract}

Correspondence: Michael C. Fontaine, Fax: (+31)50-363-9620;

E-mail: mikafontaine@gmail.com

${ }^{1}$ Present address: Marine Evolution and Conservation, Centre of Evolutionary and Ecological Studies, University of Groningen, PO Box 11103 CC, 9700 CC, Groningen, The Netherlands 
ecotypes diverged during the last glacial maximum (c. 23-19 kilo-years ago, kyrBP). ABC supports the hypothesis that the BS and upwelling ecotypes share a more recent common ancestor (c. $14 \mathrm{kyrBP}$ ) than either does with the European continental shelf ecotype (c. $28 \mathrm{kyrBP}$ ), suggesting they probably descended from the extinct populations that once inhabited the Mediterranean during the glacial and post-glacial period. We showed that the two Atlantic ecotypes established a narrow admixture zone in the Bay of Biscay during the last millennium, with highly asymmetric gene flow. This study highlights the impacts that climate change may have on the distribution and speciation process in pelagic predators and shows that allopatric divergence can occur in these highly mobile species and be a source of genetic diversity.

Keywords: allopatric divergence, Cetacea, climate changes, speciation, upwelling

Received 5 June 2013; revision received 11 May 2014; accepted 21 May 2014

\section{Introduction}

Intraspecific differentiation along contiguous geographical areas due to vicariance or geographical barriers is common in nature (Wiley 1988). However, in the marine environment, movements are typically unrestricted over vast distances for highly mobile species such as cetaceans. This raises the question of how populations become genetically isolated and subsequent speciation takes place (Palumbi 1994). Despite their high dispersal ability, cetaceans show substantial population structure, sometimes over a small geographical scale, not necessarily associated with geographic distance (e.g. Palumbi 1994; Hoelzel 1998; Fontaine et al. 2007). In some cases, oceanographic processes and (or) behavioural traits explain a high level of population differentiation (e.g. Fontaine et al. 2007; Pastene et al. 2007; Pilot et al. 2010; Foote et al. 2011; Louis et al. 2014). Usually, prey availability, prey choice, social structure and/or other factors such as habitat availability, predator and competition pressure are involved in driving dispersal patterns and extent (e.g. Hoelzel 1998). The question thus revolves around deciphering which current and/or historical mechanism(s) contributed to genetic structuring in the absence of obvious dispersal barriers. Furthermore, determining how past climate change has influenced the diversification of lineages can help us understand how speciation process takes place in marine pelagic species and how anthropogenic climate changes will impact their persistence.

Harbour porpoise (Phocoena phocoena) is one of the smallest and most abundant coastal cetaceans, widely distributed in cold to temperate coastal waters of the northern hemisphere (Gaskin 1984). They are currently divided into three subspecies: P. p. vomeria in the North Pacific, P. p. phocoena in the North Atlantic and P. p. relicta in the Black Sea (BS; Gaskin 1984; Rosel et al. 1995). The population genetic structure of western Palearctic harbour porpoises (i.e. eastern North Atlantic and BS) has been assessed in several studies during the last
20 years (e.g. Andersen et al. 2001; Tolley \& Rosel 2006; Fontaine et al. 2007; Wiemann et al. 2010). Analyses of mitochondrial sequences and microsatellites data revealed that harbour porpoises from the BS and the North Atlantic are genetically divergent and follow independent evolutionary trajectories (Rosel et al. 1995; Fontaine et al. 2010). They would have diverged within the last 7000 years before present (yrBp; Fontaine et al. 2010). Fontaine et al. (2010) hypothesized that during the last glacial maximum (LGM, 26.5-19 kyrBp; Clark et al. 2009), habitat conditions were strikingly different from the current warm and oligotrophic state of the Mediterranean Sea, with far colder conditions and suitable habitats for cold-water species such as harbour porpoises. The postglacial warming would have led to habitat fragmentation and eventually to the retreat of the species from the Mediterranean Sea. Some individuals would, however, have survived in the BS after reconnection to the Mediterranean Sea c. 8400 yrBp (Fontaine et al. 2010, 2012).

In the North-East (NE) Atlantic, the population genetic structure of the harbour porpoise is typically weak across the European continental shelf; from the northern Bay of Biscay to Norway and Iceland (Andersen et al. 2001; Tolley \& Rosel 2006; Fontaine et al. 2007; Wiemann et al. 2010; Alfonsi et al. 2012). However, further south, harbour porpoises in the Iberian waters showed a distinct genetic ancestry from porpoises north of the Bay of Biscay and a higher divergence in allelic frequencies than expected under geographic distance alone, suggesting that population genetic structuring, in this part of the NE Atlantic, could be due to environmental barrier to gene flow (Fontaine et al. 2007). The shallow genetic divergence between Iberian porpoises (IB) and those north of the Bay of Biscay supported a recent divergence event within the last two millennia, correlating with the last major cold stage in Europe known as the Little Ice Age c. 600 years ago (Fontaine et al. 2010).

Harbour porpoises also occur further south of the Iberian peninsula along the coast of Mauritania, but 
they are poorly known (Smeenk et al. 1992; Donovan \& Bjørge 1995). They inhabit the Eastern Central Atlantic Upwelling system with its northern limit encompassing the Atlantic coasts of Iberia (Arístegui et al. 2009). Despite the great distance separating them $(\sim 2000 \mathrm{~km}$, Fig. 1), Iberian and Mauritanian porpoises both rely on an interconnected upwelling system. Stomach content analyses, stable isotopes and field surveys suggest that their habitat and diet differ from the porpoises living on the European Continental Shelf north of the Bay of Biscay (Pierce et al. 2010; Pinela et al. 2010; Méndez-Fernandez et al. 2013). These ecological differences are further supported by morphological differences, with harbour porpoises from Iberia and Mauritania having a larger body size $(\sim 2 \mathrm{~m})$ than individuals found further North on the European Continental Shelf ( 1.5 m; Smeenk et al. 1992; Donovan \& Bjørge 1995). The ecological and morphological similarities between Iberian and Mauritanian porpoises suggest they inhabit the same kind of environment and rely on similar feeding resources. They could also descend from a recent ancestral population in the past and hence have been subjected to the same kind of environmental pressures. Previous studies suggest that BS porpoises are probably the descendants from Mediterranean porpoises that once existed in the eastern side of the Mediterranean Sea during or after the LGM (Fontaine et al. 2010, 2012).
We hypothesize that Iberian and Mauritanian porpoises could be the descendants of the porpoises that used to live in the western Mediterranean Sea. Their close proximity to the Gibraltar Strait, reports of some movements of Atlantic Iberian porpoises into the Mediterranean Sea (Frantzis et al. 2001), and their similar ecology and morphology lend some credibility to this hypothesis.

We tested our hypothesis by examining the genetic structure of the harbour porpoise in the western Palearctic waters (Fig. 1). We genetically characterized the Mauritanian populations, for the first time to our knowledge, using multiple samples and combined them with the samples used in Fontaine et al. (2007). We analysed the genetic relationships among porpoises and their demographic history using microsatellite loci (Fontaine et al. 2007) and new sequences from one-third of the mitochondrial genome; combining fast and slow evolving loci can help capture demographic events occurring at different timescales (Cornuet et al. 2010; Fontaine et al. 2012). Specifically, we investigated the demographic history best describing the species genetic diversity using approximate Bayesian computation (ABC; Beaumont et al. 2002). In contrast to previous attempts (e.g. Fontaine et al. 2010), ABC provides a powerful and flexible approach based on coalescent simulations capable of considering all populations into a unified statistical framework, tests for alternative demographic histories, identifies which

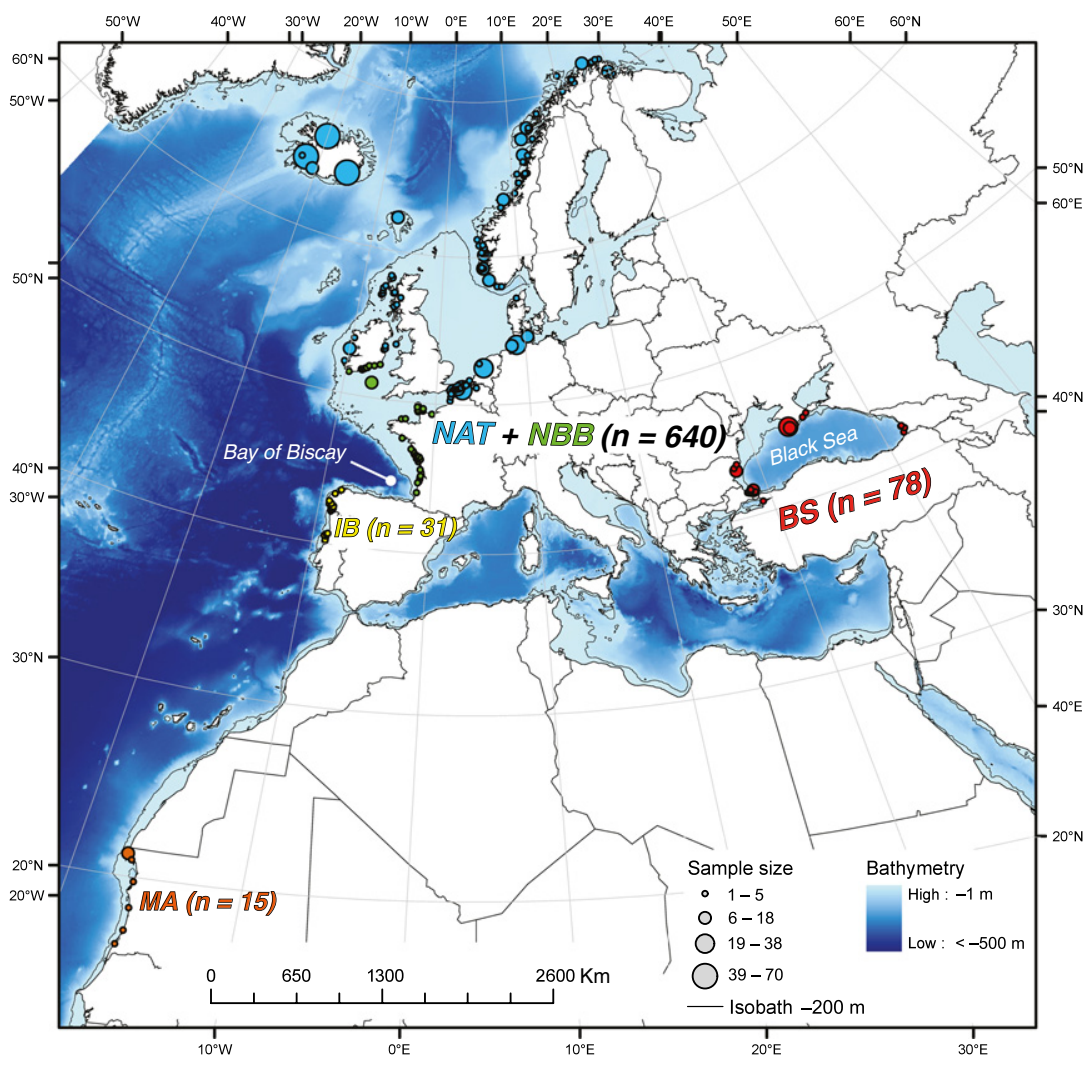

Fig. 1 Map of the sampling locations and genetic group included in the analyses (NAT: NE Atlantic including the northern Bay of Biscay (NBB), IB: Iberia, MA: Mauritania, BS: Black Sea). 
one best fits with the data and estimates the demographic parameters of interest (e.g. effective population size, divergence, admixture and times of these events; Beaumont 2010). This unprecedented comprehensive genetic assessment allows us to investigate the porpoise population genetic structure at large in western Palearctic waters, infer the population demographic history and understand it in the light of past environmental changes. Ultimately, this study aims at understanding which factors may have shaped the divergence process between populations and how speciation process can take place in such marine predator.

\section{Materials and methods}

\section{Sampling and data collection}

We combined the genotypes at 10 microsatellite loci for the 752 samples from Fontaine et al. (2007) with the genotypes of 15 new Mauritanian samples (obtained from strandings along the Mauritanian coast, Fig. 1). DNA extraction and microsatellite genotyping followed the same protocol as described in Fontaine et al. (2007). In addition, a 5085 base-pair fragment of the mtDNA genome encompassing five coding regions (CytB, ATP6, ATP8, ND5 and COXI, Table S1, Supporting information) was obtained for a subset $(n=81$, Table S2, Supporting information) representative of the samples used for the microsatellite analysis, following the protocol provided in the Appendix S1 (Supporting information). In addition, a sample from Dall's porpoise (Phocoenoides dalli), kindly provided by the NOAA Fisheries SWFSC, was included for analyses requiring an outgroup.

\section{Comparison of genetic diversity among populations}

Variation at microsatellite loci. We compared the genetic diversity at the microsatellite loci between populations using allelic richness $(A r)$ and private allelic richness ( $p A r)$ computed with ADZE (Szpiech et al. 2008), and the observed and expected heterozygosity $\left(H_{\mathrm{o}}\right.$ and $\left.H_{\mathrm{e}}\right)$ computed with FSTAT 2.9.3 (Goudet 2001). Differences in genetic diversity between populations were tested using a Wilcoxon signed-rank (WSR) test for paired samples. Departures from the expected Hardy-Weinberg and linkage equilibrium (HWLE) may indicate further subdivisions within a given population (Wahlund effect; Hartl \& Clark 2007). Departures from HWLE were tested using exact tests implemented in GENEPOP v4 (Rousset 2008) and quantified using F-statistics (Weir \& Cockerham 1984) in FSTAT.

Variation at mtDNA loci. Variation among the mtDNA sequences was measured using haplotype diversity
$\left(H_{\mathrm{d}} \pm \mathrm{SD}\right)$ and two estimators of population genetic diversity: $\pi$, based on the average number of pairwise differences, (Tajima 1983) and $\theta_{W}$, based on the number of polymorphic sites (Watterson 1975). Both statistics $(\pi$ and $\left.\theta_{\mathrm{W}}\right)$ were estimated from the total length of the analysed fragments and expressed as per-site level of diversity, using DNASP v5.10.01 (Librado \& Rozas 2009).

Phylogenetic relationships among mtDNA haplotypes were estimated using a maximum-likelihood method using PHYML 3.0 (Guindon \& Gascuel 2003) and a GTR + I + G model of nucleotide evolution (Nabholz et al. 2007). The transition/transversion ratio, the proportion of invariable sites, the gamma distribution and the starting tree (estimated using a BIONJ algorithm) were also estimated by PHYML. The confidence in the optimized tree was estimated using 999 bootstrap replicates. The homologue sequence of Dall's porpoise was used to root the tree.

\section{Population genetic structure}

We explored the genetic relationships of the new Mauritanian samples with the other porpoises based on the nuclear microsatellite data set using Bayesian clustering algorithms of STRUCTURE v2.3.4 (Pritchard et al. 2000; Falush et al. 2003; Hubisz et al. 2009). We used the standard admixture model and the Locprior model designed to improve the ability of STRUCTURE to detect weak signals of structure and admixture without introducing bias or forcing the clustering (Hubisz et al. 2009; see Appendix S2, Supporting information for further details).

Pairwise genetic differentiation between populations at microsatellite loci was estimated with the $F_{\mathrm{ST}}$ statistics (Weir \& Cockerham 1984) estimated with FSTAT 2.9.3 (Goudet 2001), and the significance was tested using an exact test implemented in GENEPOP v4.0. For mtDNA, we used the $F_{\mathrm{ST}}$ statistics estimated from the average number of differences within and between populations (Hudson et al. 1992). Significance was tested with 1000 permutations of Hudson's nearest neighbour distance Snn statistics, which measures how often the nearest neighbour of a sequence (in sequence space) is from the same population (Hudson 2000). Mitochondrial divergence between groups was estimated using the Jukes-Cantor corrected average nucleotide divergence $\left(D_{\mathrm{a}}\right)$ (Nei \& Li 1979). All calculations were performed using DNASP v5.10.01 (Librado \& Rozas 2009).

\section{Evidence for changes in effective population size}

We investigated changes in effective population size in each population by testing for deviations of the mitochondrial site frequency spectrum from the neutral 
model using two statistics indicative of population size changes or selective process: Tajima's D (Tajima 1983) and $\mathrm{Fu}$ and $\mathrm{Li}^{\prime} \mathrm{s} D^{*}$ (Fu \& $\mathrm{Li}$ 1993). We performed 10000 rounds of coalescent simulations conditional on $\theta_{W}$ to test the statistical significance of these parameters, as implemented in DNASP v5.10.01 (Librado \& Rozas 2009).

We further analysed demographic changes in effective population size back to the time of the most recent common ancestor (TMRCA) within each population using the Bayesian skyline plot (BSP; Ho \& Shapiro 2011) applied on the complete mitochondrial sequences. Analyses were performed in BEAST 1.7.5 (Drummond et al. 2005; Drummond \& Rambaut 2007) using a HKY model of nucleotide substitution (Hasegawa et al. 1985), allowing for two different substitution rates between the third codon position and the two others, and a strict clock rate. The BSP is a piecewise-constant coalescent model, in that it allows several different constant population sizes to have existed throughout the sampled evolutionary history (in this case, 10 different population sizes) and then averages these estimates across the a posteriori-sampled trees. For each analysis, three Monte Carlo Markov chains (MCMC) were run for $10^{8}$ iterations, with samples drawn from the posterior every 3000 iteration. Convergence of the runs was checked by computing the MCMC autocorrelation and effective sample size and by comparing the consistency of the
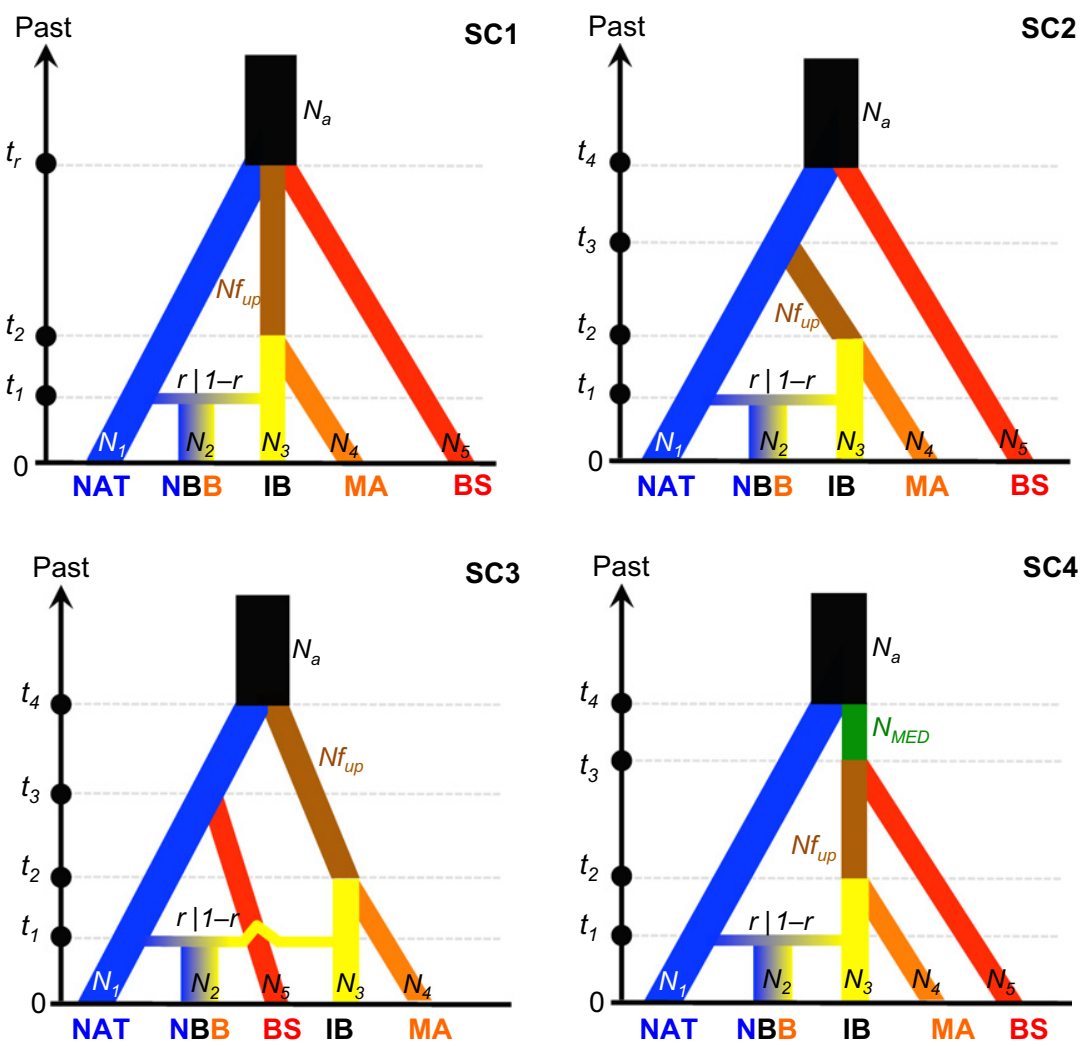

results provided by independent analyses. After checking for appropriate mixing and convergence, the first $10 \%$ of samples from the posterior were discarded and the remainder combined for parameter inferences. BSPs were estimated using TRACER v1.5 (Rambaut 2007).

\section{Genetic inference of the population demographic history}

We tested four plausible demographic scenarios of population evolution (Fig. 2) based on the current genetic structure: The first scenario (SC1) models a radiation process where the three main groups of porpoises - that is, the NE Atlantic continental shelf group (NAT), the group of porpoises inhabiting the upwelling waters (UP) including Iberian (IB) and Mauritanian (MA) populations, and the BS population - would have split at the same time from a common ancestor. This event would have been followed by the split of UP into IB and MA and by an admixture event between NAT and IB from which would have resulted the porpoises found in the northern part of the Bay of Biscay (NBB). The following alternative scenarios differ from the first one and from each other by the branching topologies of the three main groups (NAT, UP and BS). The second scenario (SC2) assumes that BS splits first from NAT, followed by the split of UP, as previously suggested in Fontaine et al. (2010). SC3 assumes the reverse

Fig. 2 Diagram of the demographic scenarios tested using the approximate Bayesian computation (ABC) approach (see the text for a description of each scenario, and Fig. 1 for population codes). The different segment colours on the population trees refer to different effective population sizes $(N)$. The parameters $(N$, time $t$, admixture rate $r)$ of each model are indicated on each graph (see the text and Table S3, Supporting information for more details). The timescale is indicated by an arrow and measured backward in generations starting from present. 
hypothesis for which UP would have split first from NAT, followed by the split of BS. The fourth scenario (SC4) assumes that porpoises from UP and BS would have shared a common ancestor before having a split from NAT. By simulating a common ancestor $\left(N_{\text {med, }}\right.$ Fig. 2) between UP and BS compared with NAT, this scenario aims at testing the hypothesis that porpoises from upwelling waters and the BS could be descendants from an ancestral group that could have existed in the Mediterranean Sea. Each scenario included the following events: population split, change in effective population sizes (symbolized by different coloured segment on the population graphs, Fig. 2), an admixture event between NAT and IB from which would have resulted the NBB porpoises, with respective admixture proportion $r$ and $(1-r)$, and the time of each of these events.

We combined and analysed both the microsatellite and mitochondrial DNA data using the DIYABC-v2.0.4 program (Cornuet et al. 2014). For each scenario, we simulated 1 million data sets. The parameters of each model (i.e. population sizes, admixture rates, timings of demographic events, mutation rates) were considered as random variables drawn from prior distributions (see Fig. 2 for the list of demographic parameters and Table S3, Supporting information for details on the prior settings). DIYABC draws a random value for each parameter from its prior distribution and performs coalescent-based simulations to generate simulated samples with the same number of gene copies and loci per population as observed in the real samples. For each simulated data set, a set of summary statistics is generated, which are also estimated for the observed data. A Euclidean distance $\delta$ is then calculated between the statistics obtained for each normalized simulated data set and those for the observed data set (Beaumont et al. 2002). Details on the mutation model for microsatellite loci and mtDNA locus and the summary statistics used by DIYABC are provided in Appendix S3 (Supporting information).

Model choice procedure. The posterior probability of each scenario was estimated using a polychotomous logistic regression (Cornuet et al. 2008, 2010) on the $1 \%$ of simulated data sets closest to the observed data set, subject to a linear discriminant analysis as a preprocessing step (Estoup et al. 2012). The selected scenario was that with the highest posterior probability value with a nonoverlapping 95\% confidence interval. We evaluated the ability of the ABC approach to discriminate between the tested scenarios by analysing simulated data sets with the same properties as our real data set. Following Cornuet et al. (2010), we estimated the type-I error probability as the proportion of instances in which the selected scenario did not give the highest posterior probability among the competing scenarios, for 1000 simulated data sets generated under the best-supported model. We estimated the type-II error, by simulating 1000 data sets for each alternative scenario and calculating the mean proportion of instances in which the best-supported model was incorrectly selected as the most likely model.

Parameter estimation and goodness of fit. We estimated the posterior distributions of each demographic parameter under the best demographic model, by carrying out local linear regressions on the closest $1 \%$ of $10^{6}$ simulated data sets, after the application of a logit transformation to parameter values (Cornuet et al. 2008). We evaluated whether the best model-posterior distribution combination was better able to reproduce the observed data compared with the alternative scenarios using the model checking procedure in DIYABC. Model checking was carried out by simulating 1000 pseudo-observed data sets under each studied model-posterior distribution combination, with sets of parameter values drawn with replacement from the 1000 sets of the posterior sample. This generated a posterior cumulative distribution function for each simulated summary statistics, from which we were able to estimate the $P$-value of the deviation of the observed value of each statistic from its simulated distribution under the best demographic model.

\section{Estimation of gene flow between NE Atlantic populations}

We used Migrate-N 3.5.1 (Beerli 2006, 2009) to estimate the population genetic diversity $(\theta)$ and the migration rate $(M)$ between populations using the microsatellite data set. The analysis was conducted only on Atlantic populations, modelling migration rates between adjacent populations. As in the $\mathrm{ABC}$ analyses, we considered the harbour porpoises from the Bay of Biscay as a distinct entity. This simplified model accounting for four groups (NAT, NBB, IB and MA) reproduced closely the linear distribution of the populations along the NE Atlantic coasts (Fig. 1) and allowed minimization of convergence issues that were encountered with more complex model settings (result not shown).

We used the Bayesian approach (Beerli 2006, 2009), conducting several independent analyses using the following settings. We assumed that microsatellites evolved following a Brownian motion model, which is very close to the exact stepwise-mutation model. Five replicates of the MCMC were run for $10^{5}$ steps recorded every 200 steps, making a total of $10^{8}$ sampled parameter values by the MCMC. We discarded the first $10^{4}$ steps as burn-in and obtained the marginal posterior parameter distributions from the remaining steps. To ensure good mixing, we used four parallel Markov chains under a static heating scheme (temperatures: $10^{4}$, 
3, 1.5 and 1.0). Convergence of the runs was checked by computing the MCMC autocorrelation and effective sample size and by comparing the consistency of the results provided by independent analyses.

\section{Results}

\section{Genetic diversity}

Microsatellite loci. Harbour porpoises from Mauritania (MA), Iberia (IB) and the BS displayed comparable genetic diversity at microsatellite loci (Tables 1 and S4, Supporting information), as quantified using allelic richness $(A r)$, private allelic richness $(p A r)$ and expected heterozygosity $\left(H_{\mathrm{e}}\right)$ (WSR tests, $P>0.05$ for all pairwise comparisons). All genetic diversity measures in these populations were significantly lower than the values observed in populations north of the Bay of Biscay (Table 1 and S4, Supporting information, WSR test $P<0.05)$. Furthermore, only the porpoises found north of the Bay of Biscay displayed a significant departure from Hardy-Weinberg expectations at all but two loci (Table S4, Supporting information), which is attributed to an isolation-by-distance pattern (Fontaine et al. 2007).

MtDNA locus. Genetic diversity at the mitochondrial genome (Table 1) followed a similar pattern of variation as nuclear microsatellite loci. Of the $5085 \mathrm{bps}$, we observed 197 segregating sites (85 singletons and 112 shared sites) defining 59 distinct haplotypes (haplotype diversity, $H_{\mathrm{d}}$ : 0.989). The mtDNA nucleotide diversity values $\left(\pi\right.$ and $\theta_{\mathrm{W}}$ ) were lowest for the Iberian and Mauritanian populations, lower than for the BS population, which in turn were lower than those observed in the NE Atlantic population (NAT).

\section{Population structure and divergence}

Three distinct mitochondrial clades. The maximum-likelihood estimation of the phylogenetic relationship among the mtDNA haplotypes revealed three main lineages with a strong geographic component (Fig. 3): (i) a BS haplogroup comprised of porpoises from the BS; (ii) a NAT haplogroup composed of porpoises sampled north of the Bay of Biscay; and (iii) an UP haplogroup composed of porpoises from Iberian and Mauritanian waters, further clustering into distinct subgroups [Iberian (IB) and Mauritanian (MA)]. Some porpoises carrying $I B$ haplotypes were also found north of the Bay of Biscay and in Mauritanian waters. Each lineage was highly supported by bootstrap values $>94 \%$, except NAT which received weaker support (79\%, Fig. 3). There was also a polytomy of the three haplogroups (NAT, UP and BS) with weak bootstrap value of $48 \%$,

Table 1 Genetic diversity at the 10 microsatellite loci and mitochondrial locus

\begin{tabular}{|c|c|c|c|c|c|}
\hline & All & NAT & Iberia & Mauritania & Black Sea \\
\hline \multicolumn{6}{|l|}{ Microsatellites } \\
\hline$N_{\text {Mic. }} \pm \mathrm{SD}$ & & 617 & 30 & 13 & 78 \\
\hline$A r^{\dagger} \pm \mathrm{SD}$ & & $6.0 \pm 0.8$ & $3.9 \pm 0.7$ & $3.7 \pm 0.7$ & $3.4 \pm 0.4$ \\
\hline$p A r^{\dagger} \pm \mathrm{SD}$ & & $1.6 \pm 0.3$ & $0.4 \pm 0.2$ & $0.1 \pm 0.1$ & $0.4 \pm 0.1$ \\
\hline$H_{\mathrm{o}} / H_{\mathrm{e}}$ & & $0.73 / 0.77$ & $0.57 / 0.56$ & $0.62 / 0.58$ & $0.50 / 0.49$ \\
\hline$F_{\mathrm{IS}}$ & & $0.049^{* * *}$ & -0.016 & 0.056 & -0.02 \\
\hline \multicolumn{6}{|l|}{ mtDNA } \\
\hline$N_{\text {mtDNA }}$ & 81 & 36 & 19 & 14 & 12 \\
\hline$S$ & 197 & 144 & 19 & 14 & 29 \\
\hline Singl. & 85 & 67 & 11 & 1 & 26 \\
\hline Shared P. & 112 & 77 & 8 & 13 & 3 \\
\hline \#hap. & 59 & 28 & 14 & 7 & 11 \\
\hline$H_{\mathrm{d}}(\%)$ & $98.9 \pm 0.4$ & $98.1 \pm 1.3$ & $94.7 \pm 3.8$ & $90.1 \pm 4.6$ & $98.5 \pm 4.0$ \\
\hline$K$ & 26.76 & 23.73 & 3.26 & 3.67 & 5.42 \\
\hline$\pi(\%)$ & $0.53 \pm 0.02$ & $0.47 \pm 0.03$ & $0.06 \pm 0.01$ & $0.07 \pm 0.02$ & $0.11 \pm 0.02$ \\
\hline$\theta_{\mathrm{W}}(\%)$ & 0.80 & 0.69 & 0.11 & 0.09 & 0.19 \\
\hline$D$ & -1.16 & -1.20 & $-1.65^{*}$ & -0.67 & $-1.95^{* *}$ \\
\hline$D^{*}$ & $-2.81^{*}$ & $-6.66^{* * *}$ & -1.56 & 1.17 & $-2.36^{*}$ \\
\hline
\end{tabular}

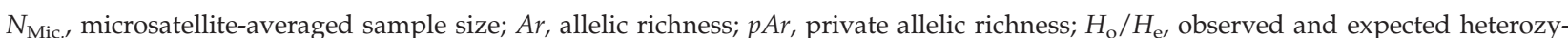
gosity; $F_{\mathrm{IS}}$, fixation index of Weir \& Cockerham (1984); $N_{\mathrm{MtDNA}}, \mathrm{MtDNA}$ sample size; $S$, segregating sites; Singl., singleton; Shared P., shared polymorphism; \#hap., number of haplotypes; $H_{\mathrm{d}}$, haplotypic diversity; $K$, average nucleotide differences; $\pi$, nucleotidic diversity; $\theta_{\mathrm{W}}$, theta from $S ; \theta_{\pi}$, theta from $\pi ; D$, Tajima' $\mathrm{D} ; D^{*}, \mathrm{Fu}$ and $\mathrm{Li}^{\prime} \mathrm{S} D^{*}$.

The significance of $D$ and $D^{*}$ values was estimated using 10000 coalescent simulations.

$* P<0.05 ; * * P<0.01 ; * * * P<0.001$.

'Standardized for a sample size of 11 individuals. 


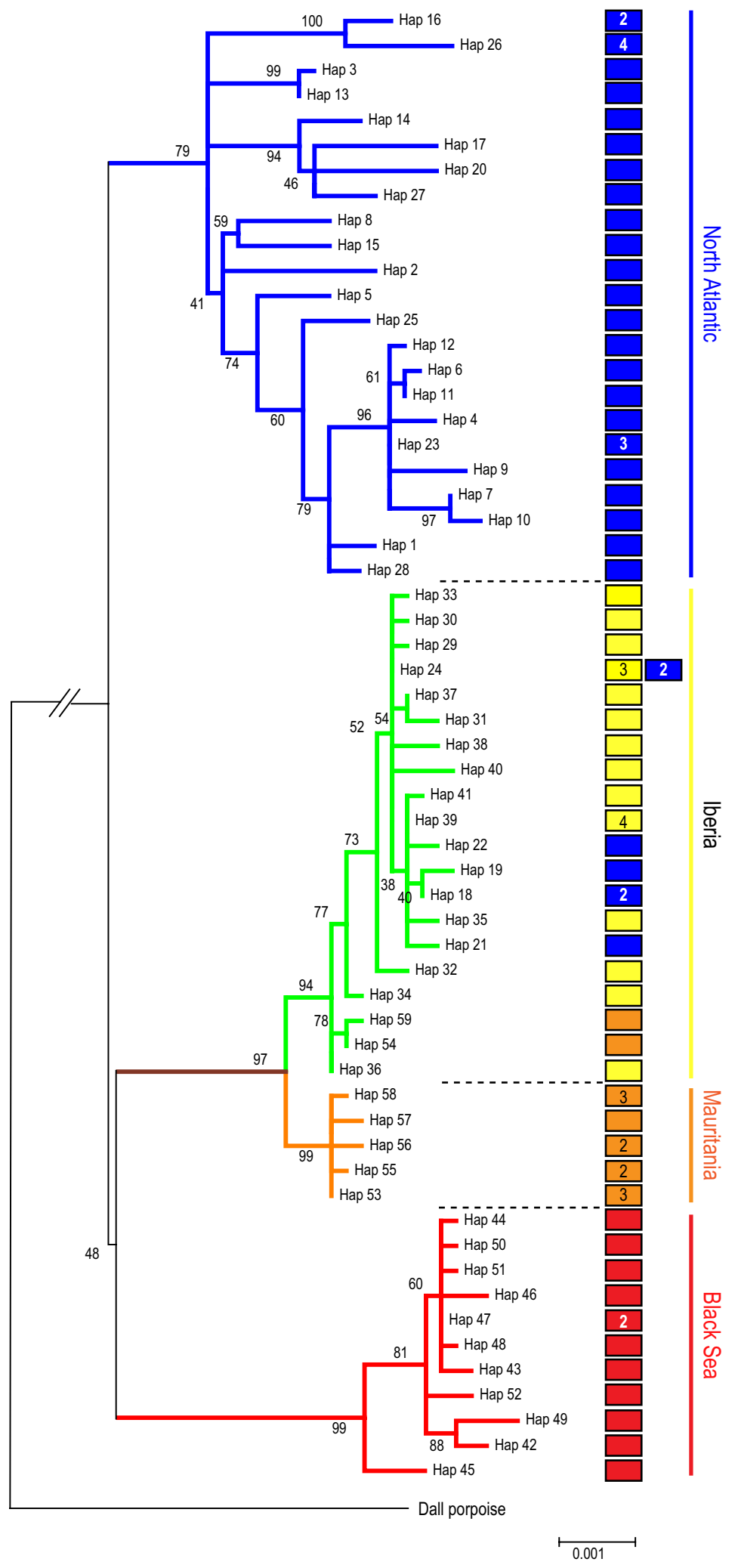

Fig. 3 Maximum-likelihood mitochondrial phylogeny. Numbers at the nodes are the bootstrap branch supports. Colours of the branches highlight the four lineages identified, and the colour-coded boxes on the right show the geographic locations where the haplotypes were found (blue: NAT; yellow: Iberia; orange: Mauritania; red: Black Sea). The numbers within the boxes refer to the number of individuals carrying this haplotype. No number means that this haplotype was observed only once. 
possibly supporting the hypothesis that UP and BS have a common mitochondrial ancestor.

The net divergence $\left(D_{\mathrm{a}}\right)$ between groups ranged from $0.15 \%$ for IB-MA to $0.71 \%$ for BS-IB (Fig. 3 and Table S5, Supporting information). The level of divergence between the UP lineage (i.e. IB and MA) and the BS or NAT lineages was of the same magnitude as the divergence of the BS with other groups, suggesting they diverged within a similar time frame. The level of divergence of the three main lineages is, however, one order of magnitude lower than the average net divergence between harbour porpoises and the most closely related species, Dall's porpoise $\left(D_{\mathrm{a}}=6.69 \pm 0.1 \%\right)$.

A structure supported by the clustering analyses of microsatellite loci. The STRUCTURE Bayesian clustering analyses on microsatellite data identified three distinct genetic clusters (Fig. S1, Supporting information). Consistent with previous results (Fontaine et al. 2007), porpoises from the BS clustered separately from the other Atlantic porpoises (Figs S2 and S3, Supporting information). Porpoises from the Iberian waters clustered with the new samples from Mauritania (Figs S2 and S3, Supporting information), constituting a coherent group of porpoises living in the upwelling zones (UP). This grouping persisted even when testing higher numbers of putative clusters (Figs S2 and S3, Supporting information). They were, however, distinct from each other without evidence of admixture when analysed separately from other populations using the LocPrior model (Fig. S3, Supporting information). The third cluster (Figs S2 and S3, Supporting information) grouped all porpoises from the European continental shelf, that is, from the French coasts of the Bay of Biscay northward to the arctic waters of Norway and Iceland, the 'NE Atlantic' cluster (NAT). While the standard admixture model (Fig. S2, Supporting information) produced a noisy admixture pattern, the use of sample locality as additional prior information in the Bayesian inference (LocPrior model) significantly reduced the variation in admixture proportions (Fig. S3, Supporting information). Porpoises in the northern Bay of Biscay, the Channel and Celtic Sea showed a clear signature of admixture with $0.33( \pm 0.09)$ in average $( \pm S D)$ of their ancestry drawn from the upwelling population (i.e. IB and MA) and $0.66( \pm 0.09)$ from the NAT group. The other NAT individuals showed no evidence of admixture.

Differences in allelic or haplotype frequencies, respectively, for microsatellite or mtDNA loci estimated using $F_{\mathrm{ST}}$ values between each pairwise comparison were all highly significant $(P<0.001$, Table S5, Supporting information). The highest $F_{\mathrm{ST}}$ values for microsatellite loci were observed between the BS and IB $\left(F_{\mathrm{ST}}=0.31\right)$ or MA $\left(F_{\mathrm{ST}}=0.28\right)$ and lowest between IB and MA porpoises $\left(F_{\mathrm{ST}}=0.07\right)$. Similarly for mtDNA, the $F_{\mathrm{ST}}$ values were the highest between the BS and IB $\left(F_{\mathrm{ST}}=0.89\right)$ or $\mathrm{MA}\left(F_{\mathrm{ST}}=0.88\right)$ and lowest between NAT and IB $\left(F_{\mathrm{ST}}=0.55\right)$ or MA $\left(F_{\mathrm{ST}}=0.54\right)$.

\section{Mitochondrial evidence of demographic changes in population sizes}

We detected significant departures of the mitochondrial site frequency spectrum from neutral expectations, especially for the BS population, with significant negative values for both the Tajima's $D$ and the $\mathrm{Fu}$ and Li's $D^{*}$ statistics (Table 1). The signal was weaker in the NAT and IB populations with only one of the two statistics showing a significant negative value. The MA population did not display any significant departure from neutral expectations (Table 1). Negative values are characteristic of an excess of singleton mutation in the population resulting from either a demographic expansion or selective sweeps.

The coalescence-based Bayesian skyline plot (BSP) provides additional details on how mtDNA diversity changed through time, back to the most recent common ancestor (MRCA). Assuming a substitution rate of $5 \times 10^{-8}$ substitutions per-site and per-year (Nabholz et al. 2007), the BSP shows that the lower $95 \%$ bound of the time to the MRCA is $50 \mathrm{kyr}$ before present (вр) in the NAT group (Fig. 4), which is an order of magnitude older than the two upwelling groups (4 kyrBP in IB and 6 kyrBP in MA) and the BS group (8 kyrBp). Consistent with Tajima $D$ and $\mathrm{Fu}$ and $\mathrm{Li} D^{*}$ statistics, the BS group showed the most obvious signal of expansion c. 8 kyrBP. The IB group also revealed this signature, although the magnitude of the expansion was more modest. The MA group did not show any major change in effective population size. The NAT group showed an ancient increase in effective population size dating back c. 40 kyrBp, followed by a slight steady increase until recently where the effective population size reached an inflexion point.

\section{Genetic inference of the population demographic history}

We tested which historical demographic scenario could best explain the nuclear microsatellite and mtDNA data by comparing four demographic scenarios of population evolution (Fig. 2) using an ABC approach. Estimations of the posterior probability $(\mathrm{PPr})$ for each scenario provided unambiguous support for the scenario SC4, with a probability of $47.5 \%$ and a $95 \%$ CI of $46.3-48.6$, not overlapping with any other scenarios (Table S6, Supporting information). This scenario assumes that, before having split from each other, harbour porpoises 


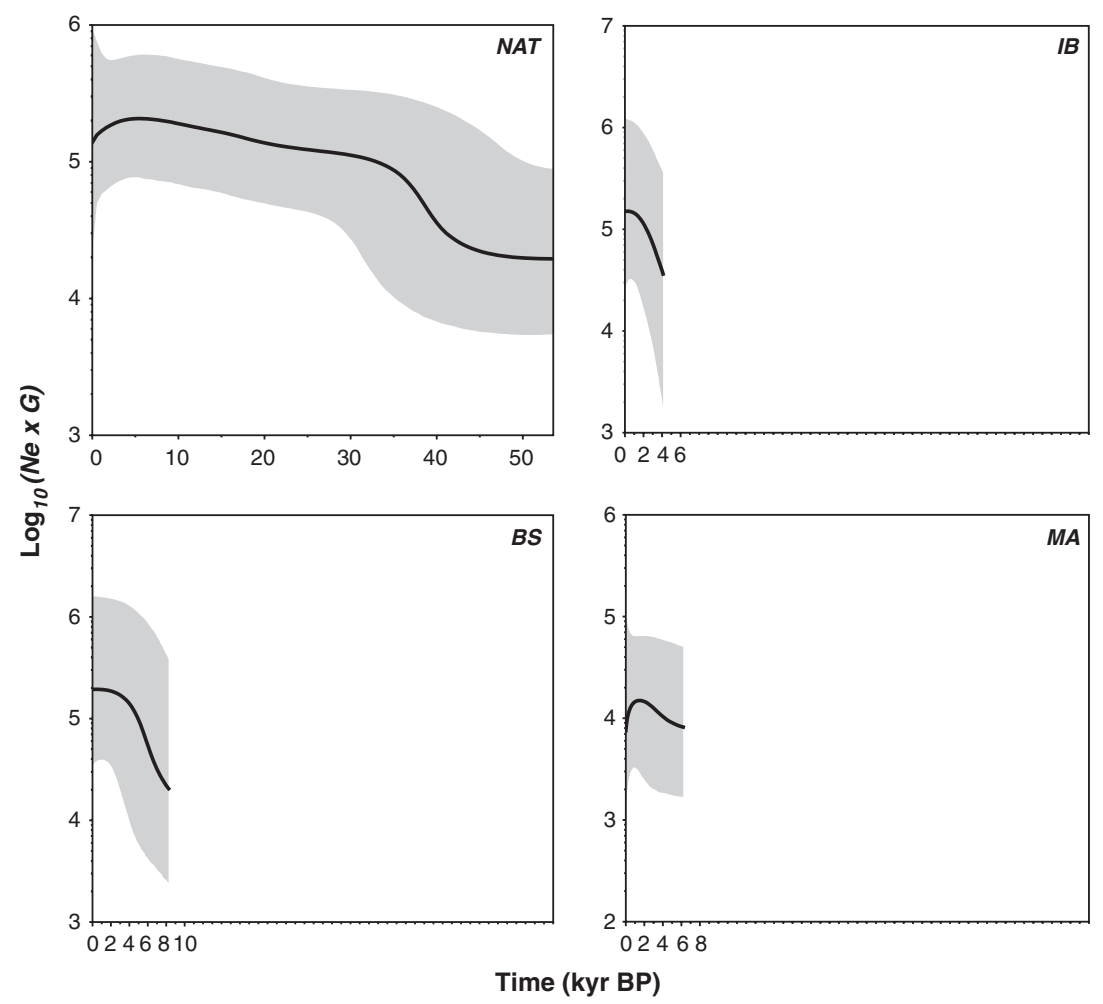

Fig. 4 Bayesian Skyline Plots (BSPs) showing the temporal changes in mtDNA diversity. The $x$-axis is in calendar years. The temporal span stops at the lower bound of the $95 \%$ CI of the estimated time of the most recent common ancestor; the $y$-axis shows the genetic diversity expressed as the product of effective female population size and generation time.

from the upwelling zones and the BS shared a common ancestral population that split from the NAT group. The scenario SC1 assuming a trifurcation process (Fig. 2) was the second best-supported scenario (33.6\%, 95\% CI: 32.3-34.9), and the two other alternatives (SC2 and SC3) were the least-supported scenarios (PPr $\leq 12.5 \%$, Table S6, Supporting information). Power analyses based on test data sets simulated under the four scenarios indicated that, given the size and polymorphism of our data set, the method has high power to distinguish between the competing scenarios tested (for details on type-I and type-II error rates, see the Appendix S3, Tables S6 and S7, Supporting information).

The estimated parameters under this SC4 scenario were consistent with the descriptive statistics of microsatellite and mtDNA loci (Tables S8 and S9, Supporting information). The estimated population genetic diversity (Table S9, Supporting information) was comparable between the BS, Mauritanian and Iberian groups, but much lower than that found in the Bay of Biscay, itself lower than the genetic diversity found further north. The contribution of the IB and NAT groups in the genetic make-up of porpoises from the Bay of Biscay was $21 \%$ (90\% CI: 10-41) and 79\% (90\% CI: 59-90), respectively, in the same range as the values estimated with STRUCTURE. The estimated date of admixture $\left(t_{1}\right)$ was 592 yrBP (90\% CI: 221-2150, Fig. 5), assuming a generation time of 10 years (Birkun \& Frantzis 2008). The estimated divergence time between IB and MA porpoises $\left(t_{2}\right)$ was 3110 yrBP (90\% CI: 1360-14 100), between BS and UP groups $\left(t_{3}\right)$ was 13800 yrвp $(90 \%$ CI: 8730-38 800), and between the NAT and the ancestral population common to BS and UP was 27900 yrBP (90\% CI: 14 400-70 700) (Fig. 5).

\section{Asymmetric migration between the Atlantic populations}

Bayesian estimates of effective number of migrants per generation between each pair of adjacent populations in the NE Atlantic from the microsatellite data are reported in Table 2. Although we considered porpoises from the Bay of Biscay (NBB) as a separate group from those further North in the NE Atlantic (NAT), the migration rate between them was high, reflecting a substantial level of genetic continuity between NBB and NAT. Nonetheless, the estimated number of effective migrants was one order of magnitude higher from NBB to NAT than in the opposite direction. The Iberian population also clearly contributed to the genetic diversity of the NBB population in the Bay of Biscay, consistent with STRUCTURE and ABC analyses and with the geographic distribution of mtDNA haplotypes (Fig. 3). On the other hand, the estimate of gene flow in the reverse direction (NBB to IB) was not statistically different from 0 . Also in agreement with the geographic distribution of mtDNA haplotypes (Fig. 3), migration between the Mauritanian and Iberian porpoises was low with 


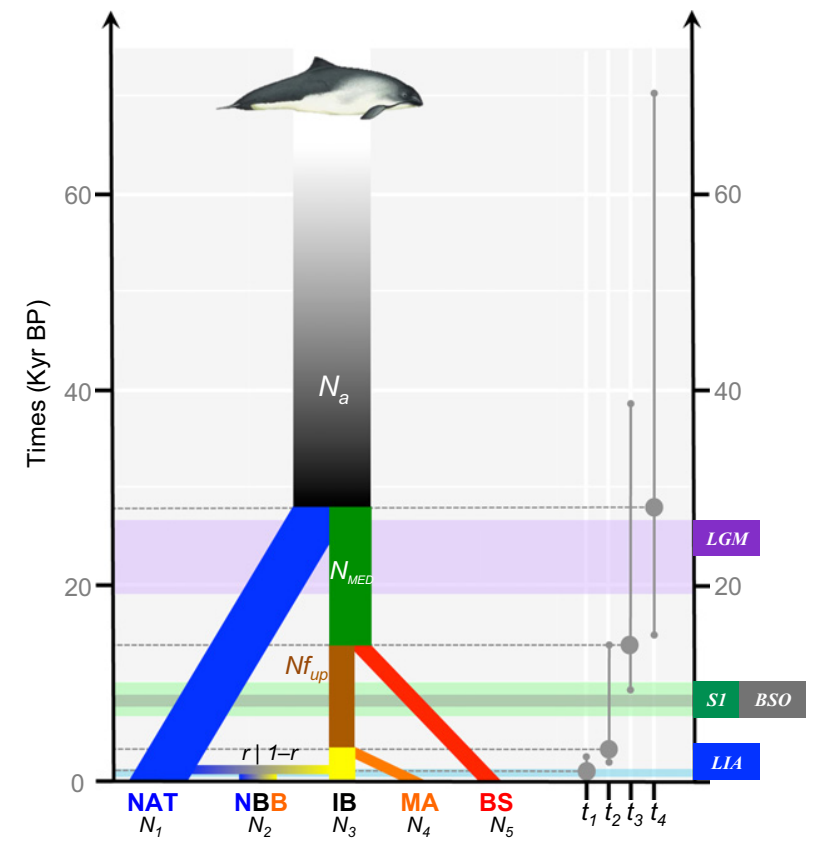

Fig. 5 Demographic scenario selected by the approximate Bayesian computation $(\mathrm{ABC})$ analysis. Demographic events are scaled according to the estimated time of occurrence, in thousands of years before present. Time estimates are provided as the mode and $90 \%$ highest probability density intervals (grey dots and error bars). Major environmental changes potentially related to the demographic history of harbour porpoises are also plotted: last glacial maximum period (LGM, c. 23-19 kyrBP; Clark et al. 2009), Mediterranean Sapropel S1 period (c. 9.5-6.5 kyrBp; e.g. Spötl et al. 2010; Roberts et al. 2011), flooding of the Black Sea (BSO, c. 8.4-9.4 kyrBP; Major et al. 2006; Giosan et al. 2009) and Little Ice Age (LIA, c. 250-700 yrip; Osborn \& Briffa 2006).

Table 2 Estimated number of effective migrants per generation (mode and quantiles, $Q$ ) between the four Atlantic groups

\begin{tabular}{lrrrrr}
\hline Population & $Q_{2.5}$ & \multicolumn{1}{c}{$Q_{25}$} & Mode & $Q_{75}$ & $Q_{97.5}$ \\
\hline $4 N m_{\mathrm{NAT} \rightarrow \mathrm{NBB}}$ & 4.0 & 8.3 & 11.3 & 14.4 & 18.9 \\
$4 N m_{\mathrm{NBB} \rightarrow \mathrm{NAT}}$ & 187.7 & 246.1 & 267.9 & 294.9 & 367.5 \\
$4 N m_{\mathrm{NBB} \rightarrow \mathrm{IB}}$ & 0.0 & 0.0 & 0.1 & 3.5 & 9.1 \\
$4 N m_{\mathrm{IB} \rightarrow \mathrm{NBB}}$ & 25.3 & 60.0 & 72.1 & 94.4 & 141.9 \\
$4 N m_{\mathrm{IB} \rightarrow \mathrm{MAU}}$ & 0.0 & 0.3 & 3.1 & 5.3 & 10.9 \\
$4 N m_{\mathrm{MAU} \rightarrow \mathrm{IB}}$ & 0.0 & 0.0 & 0.1 & 3.7 & 9.6 \\
\hline
\end{tabular}

evidence of some gene flow from Iberia to Mauritania, but not in the reverse direction.

\section{Discussion}

\section{An unexpected deep mitochondrial divergence}

In this study, we show that harbour porpoises living in the upwelling zones of Iberia and Mauritania belong to a separate mitochondrial lineage, which is as divergent as the BS or the NE Atlantic lineages. This is consistent with early information that suggested harbour porpoises from Iberian and Mauritanian waters shared distinctive morphological traits, such as a larger body size than other porpoises found further North in the Atlantic or in the BS (Donovan \& Bjørge 1995). Previous genetic studies, using microsatellite loci (Fontaine et al. 2007, 2010) or short sequences from the noncoding control region of the mitochondrial genome (mtDNA-CR; Tolley \& Rosel 2006), identified Iberian porpoises as a distinct population. However, none of them captured the deep divergence we observed here using a large portion of the mitochondrial genome. The most likely explanation for the inability of microsatellite or mtDNA-CR loci to uncover this deep divergence is related to saturation effects. Microsatellite loci are highly polymorphic loci and thus subject to homoplasy (Estoup et al. 2002). With their high mutation rate, they are primarily informative for detecting recent demographic events. Although the mtDNA-CR mutation rate is slower than microsatellites, it is one or two orders of magnitude higher than the coding regions of the mitochondrial genome and three orders of magnitude higher than the nuclear genome (e.g. Alter \& Palumbi 2009). Furthermore, mutation rate is highly heterogeneous along the mtDNA-CR, with two localized hypervariable regions where most, if not all, mutations occur (Wakeley 1994; Alter \& Palumbi 2009), increasing the probability of homoplasy.

\section{A new ecotype of harbour porpoises in the North Atlantic}

Harbour porpoises from the Atlantic and the BS are currently recognized as two distinct evolutionary significant units (ESU) that are following independent evolutionary trajectories (Moritz 2002), forming the basis to recognize them as two distinct subspecies (Gaskin 1984; Rosel et al. 1995). The present study shows that these taxonomic definitions are too simplistic and that populations from Iberia and Mauritania may belong to a distinct ESU. They inhabit a distinct environment (Arístegui et al. 2009), relying on an upwelling-related trophic network (Pierce et al. 2010; Pinela et al. 2010; Méndez-Fernandez et al. 2013), which contrasts with the predominantly demersal feeding habits of porpoises from the European continental shelf (e.g. Santos \& Pierce 2003; Spitz et al. 2006). They also display distinct morphological features, in particular a larger body size (Smeenk et al. 1992; Donovan \& Bjørge 1995). The combined evidence suggests that harbour porpoises from Iberia and Mauritania could well represent a distinct ecotype from those from the NE Atlantic continental shelf waters (the continental shelf ecotype). Their 
comparable level of mitochondrial genetic divergence with the BS and NAT groups (currently recognized as subspecies), their distinct demographic history and their ecological differences (Pierce et al. 2010; Pinela et al. 2010; Méndez-Fernandez et al. 2013) suggest these porpoises should be described as a distinct entity from Phocoena $p$. phocoena. For those reasons, we suggest to increase these populations to subspecific status: Phocoena phocoena meridionalis.

\section{Postglacial divergence and fate of the Mediterranean populations}

The deep mtDNA divergence observed between porpoises from the upwellings (in Iberia and Mauritania) and the NE Atlantic is inconsistent with the previous hypothesis that genetic differentiation between these populations resulted solely from habitat fragmentation induced by the recent climate warming after the Little Ice Age (LIA; Fontaine et al. 2007, 2010). This would imply a shallower genetic divergence between the two Atlantic groups, compared with the BS group. Instead, the comparable level of divergence observed between the three groups of porpoises living on the NE Atlantic continental shelf, in the upwelling zones, and in the BS shows that they have evolved independently from each other for a substantial amount of time.

The demographic history analysis by $A B C$ suggests that harbour porpoises from the upwelling zones and the BS shared a common ancestor prior to splitting from porpoises currently living on the European continental shelf (Fig. 5). This common ancestor to the populations bordering the Mediterranean Sea supports the suspected past existence of populations in the Mediterranean Sea, now extinct. In fact, the occurrence of harbour porpoises in the BS and their current absence from the Mediterranean Sea imply that porpoises once colonized the Mediterranean from the Atlantic during a period of suitable climatic and ecological conditions (Fontaine et al. 2010). Divergence times estimate between the NE Atlantic porpoises and the hypothetical ancestor to the upwelling and BS populations ( $t_{4}$, Fig. 5) correlates with the LGM period (26.5-19 kyrBP; Clark et al. 2009). At that time, the Mediterranean was colder than present (Rohling et al. 2009) and probably more suitable for a cold-water species such as harbour porpoises. Aside from genetic data, however, there is no definitive evidence that harbour porpoises were established in the Mediterranean Sea (Frantzis et al. 2001).

The divergence between the BS and upwelling porpoises probably occurred after the LGM ( $t_{3}, c .14$ kyrBP), but before the reopening of the BS onto the Mediterranean Sea (c. 8 kyrBp; Fig. 5), suggesting that their divergence occurred during the colonization of the
Mediterranean Sea from the Atlantic. Postglacial presence in the Mediterranean Sea correlates with major postglacial environmental transitions in the Mediterranean (Roberts et al. 2011). The period from the early to midHolocene (11.4-6 kyrвp) was interspersed by nutrientrich episodes known as the Mediterranean 'Sapropel episodes' characterized by the deposition of organic-rich sediments on the seafloor, formed as a result of increased primary productivity and rearrangements of water masses (Calvert et al. 1992; Rohling et al. 2009). While this phenomena was particularly intense in the eastern Mediterranean Sea, in the western section, there were contemporaneous oceanographic and biological shifts (i.e. plankton fauna), around $8000 \mathrm{yrBP}$, as a result of increased inflow of Atlantic waters (Jimenez-Espejo et al. 2007). These novel environmental conditions may have created a rich and productive trophic network favourable to top marine predators like the harbour porpoises.

During the second half of the Holocene period (5.5 kyrBP to present), the Mediterranean progressively shifted towards warm and oligotrophic conditions, unsuitable for a cold-water- adapted species. Mediterranean porpoise populations would have been forced to retreat to areas where suitable habitat was available. The BS reconnected to the Mediterranean c. 8.4 kyrBP offered a suitable refuge for eastern Mediterranean populations. This timescale is consistent with genetic data suggesting a founder event for the BS population, as shown by the estimated mitochondrial TMRCA of BS lineage, and the demographic expansion detected by the BSP analysis (Fig. 4; Fontaine et al. 2012). In contrast, harbour porpoises from the western Mediterranean would have migrated out to the Atlantic, consistent with our results which suggest that the Iberian and Mauritanian populations are descended from the extinct western Mediterranean populations, diverging from each other c. 3.1 kyrBP (90\% CI: 1.4-14.1; Fig. 5), contemporaneous to the end of the Mediterranean Sapropel period. Overall, our inference suggest that the Iberian and Mauritanian populations were part of an extended Western Mediterranean group, which has been forced to a relictual distribution within 'local' upwelling habitats that are productive enough to meet their elevated energetic requirement (Lockyer 2007).

\section{Admixture between the upwelling and continental shelf porpoises}

We have shown that Iberian and NAT groups came into contact and established an admixture zone in the northern part of the Bay of Biscay and the Celtic Sea, most likely within the last millennium (Fig. 5). Although the Iberian group is clearly distinct from the NAT group, our results and previous ones (Fontaine et al. 2010) suggest 
significant levels of gene flow between them. This begs the question as to how the two groups remain genetically distinct despite the significant level of gene flow. Given that gene flow is highly asymmetric in the northward direction from Iberia, it appears that the genetic integrity of the Iberian group can be maintained. Such situation has been observed in other species (e.g. baboons, genus Papio; Charpentier et al. 2012).

In spite of the reasonably high dispersal ability of this species, the admixture zone remained restricted to the Bay of Biscay and has not spread northward. Although, this pattern is a snapshot in time and may certainly be more dynamic, given the estimated time of the secondary contact, this may also suggest that the two ecotypes have developed differential habitat preferences. The contact zone may have remained restricted to the Bay of Biscay because this area displays a large variety of habitats suitable for both ecotypes (Fig. 1 and Arístegui et al. 2009).

Estimates of gene flow showed that the Iberian population was a source population sending migrants to the north, with some evidence of gene flow to the south in Mauritanian waters, despite the great geographic distance. This seemingly preferential movement out of Iberian waters could be related to limited resource availability along the Iberian coast. Indeed, the upwelling habitat along the Iberian coasts is seasonal (being especially active during summer) and geographically 'small' (from Galicia to the Gulf of Cadiz; Arístegui et al. 2009). On the other hand, more permanent resources can be found on the European continental shelf to the north or alternatively far to the south in the permanent and widespread NW African upwelling (Arístegui et al. 2009). This limited availability of food resources along the Iberian coastline may not only be a strong driver of harbour porpoise dispersal, but may also be the cause of reduced population size in the region. This is suggested by low density reported by the field observations in this area ( $\leq 0.3$ individuals/ $\mathrm{km}^{2}$; Hammond et al. 2013) and by the low values of genetic diversity we observed in that area.

Recent variation in resource availability may have fostered hybridization between the two ecotypes in the Bay of Biscay. We estimated that the admixed population in the Bay of Biscay was established during the last millennium (Fig. 5). Previous estimates made using another coalescent approach explicitly modelling divergence with continuous gene flow suggested that harbour porpoises from the Iberian waters and northern Bay of Biscay shared a common ancestral population before diverging c. 200 years ago (Fontaine et al. 2010). These estimates point to the last significant cold period that affected Europe before the onset of the modern warm period, the LIA (Fig. 5; Grove 2004; Osborn \&
Briffa 2006). During the LIA, significant cooling in the North Atlantic and over Europe, in particular, had a substantial impact on terrestrial and marine ecosystems (Grove 2004). These changes are recorded in fishery records from Europe, dating back to the 10th century for some species (Alheit \& Hagen 1997). They report both significant increases in capture of cold-water fishes (e.g. herrings, Clupea harengus) as far south as in the Bay of Biscay and the southward retreat of warm-water species (e.g. sardines, Sardina pilchardus) during the LIA. Given that cold-water fishes, for example herring and sandeel (Ammodytidae spp.), are a major component of continental-shelf porpoise diet throughout its current range (Santos \& Pierce 2003; Spitz et al. 2006), it is likely that the NAT harbour porpoise's range was pushed southward into the Bay of Biscay. Likewise, the Iberian porpoises could have benefited from this increase in food resources in the Bay of Biscay, thereby fostering contact between the two groups.

\section{Conclusions}

The last glaciations in the northern hemisphere had a major impact on genetic diversity in the terrestrial environment (e.g. Hewitt 2000). Our study and previous ones (e.g. Pastene et al. 2007; Foote et al. 2011; Amaral et al. 2012; Louis et al. 2014) show this is also the case in the marine environment even in species with large dispersal abilities such as cetaceans. These reinforce the role of past variation in marine primary production as an important driver of cetacean evolution (Marx \& Uhen 2010). Past environmental variation triggered the porpoise range expansion in the Mediterranean Sea during a cold nutrient-rich period followed by its contraction and fragmentation with postglacial warming, leaving behind relict populations in fragmented habitats. These processes led to genetic and morphologic divergence of three ecotypes with potentially also some ecological specialization. The relatively narrow secondary contact zone between the two Atlantic ecotypes in the Bay of Biscay might suggest that speciation process has been initiated (Nosil et al. 2009). However, additional investigations are required to fully appreciate the genomic extent of their divergence and the dynamics of the contact zone.

Accurate characterization of demographic history is critical to improving predictions about how populations of marine mammals will respond to future changes in climate and to adapt management initiatives. Given that ecological differences among populations may lead to differential responses to climate change, our identification of a new distinct ecotype in the upwelling zones, comprised of two populations locally restricted to the coasts of Iberia and Mauritania, highlights the importance of adequate genetic sampling to correctly 
characterize the population genetic structure of a species. Further information on basic aspects of their life history, demography and ecology is greatly needed to assess the impact of incidental exploitation and the ecological process underlying their divergence.

\section{Acknowledgements}

We thank the SWFSC-NOAA Fisheries providing Dall's porpoise DNA sample, V Deffontaine and A Cornille for assistance in the laboratory, $\mathrm{P}$ Beerli for assistance with Migrate, AE Estoup and JM Cornuet for discussions on DIYABC, SJE Baird and PJ Palsbøll for their comments on the study. We also thank the editor and four anonymous reviewers for their helpful comments and suggestions. We are grateful to all the persons who contributed to the sampling and in particular A Birkun, D. Bloch, MJ Addink, C Smeenk, A Lopez, N Øien and W Dabin, and OCEAMM. This work was partly funded by the Belgian Science Policy (Project SSTC EV/12/46A) and benefited from the cluster computation facilities at the National Museum for Natural History (Paris). We thank J Pedraza Acosta for his assistance in the use of this cluster. MCF was supported during his $\mathrm{PhD}$ by fellowships from the Belgian National Fund for Scientific Research and by the AGAPE Marie-Curie Fellowship Program.

\section{References}

Alfonsi E, Hassani S, Carpentier F-G et al. (2012) A European melting pot of harbour porpoise in the French Atlantic coasts inferred from mitochondrial and nuclear data. PLOS ONE, 7, e44425.

Alheit J, Hagen E (1997) Long-term climate forcing of European herring and sardine populations. Fisheries Oceanography, 6, 130-139.

Alter SE, Palumbi SR (2009) Comparing evolutionary patterns and variability in the mitochondrial control region and cytochrome B in three species of baleen whales. Journal of Molecular Evolution, 68, 97-111.

Amaral AR, Beheregaray LB, Bilgmann K et al. (2012) Influences of past climatic changes on historical population structure and demography of a cosmopolitan marine predator, the common dolphin (genus Delphinus). Molecular Ecology, 21, 4854-4871.

Andersen LW, Ruzzante DE, Walton M et al. (2001) Conservation genetics of harbour porpoises, Phocoena phocoena, in eastern and central North Atlantic. Conservation Genetics, 2, 309-324.

Arístegui J, Barton ED, Álvarez-Salgado XA et al. (2009) Subregional ecosystem variability in the Canary Current upwelling. Progress in Oceanography, 83, 33-48.

Beaumont MA (2010) Approximate Bayesian computation in evolution and ecology. Annual Review of Ecology, Evolution, and Systematics, 41, 379-406.

Beaumont MA, Zhang W, Balding DJ (2002) Approximate Bayesian computation in population genetics. Genetics, 162, 2025-2035.

Beerli P (2006) Comparison of Bayesian and maximum-likelihood inference of population genetic parameters. Bioinformatics, 22, 341-345.
Beerli P (2009) How to use MIGRATE or why are Markov chain Monte Carlo programs difficult to use. In: Population Genetics for Animal Conservation (eds Bertorelle G, Bruford MW, Hauffe HC, Rizzoli A, Vernesi C), pp. 42-79. Cambridge University Press, Cambridge, UK.

Birkun Jr A, Frantzis A (2008) Phocoena phocoena ssp. relicta. IUCN Red List of threatened species, version 2011.1. Available from www.iucnredlist.org (accessed 5 September 2011).

Calvert SE, Nielsen B, Fontugne MR (1992) Evidence from nitrogen isotope ratios for enhanced productivity during formation of eastern Mediterranean sapropels. Nature, 359, 223 225.

Charpentier M, Fontaine MC, Cherel E et al. (2012) Genetic structure in a dynamic baboon hybrid zone corroborates behavioural observations in a hybrid population. Molecular Ecology, 21, 715-731.

Clark PU, Dyke AS, Shakun JD et al. (2009) The last glacial maximum. Science, 30, 1187-1189.

Cornuet J-M, Santos F, Beaumont MA et al. (2008) Inferring population history with DIYABC: a user-friendly approach to approximate Bayesian computation. Bioinformatics, 24, 2713-2719.

Cornuet J-M, Ravignie V, Estoup A (2010) Inference on population history and model checking using DNA sequence and microsatellite data with the software DIYABC (v1.0). BMC Bioinformatics, 11, 401

Cornuet J-M, Pudlo P, Veyssier J et al. (2014) DIYABC v2.0: a software to make approximate Bayesian computation inferences about population history using single nucleotide polymorphism, DNA sequence and microsatellite data. Bioinformatics, 30, 1187-1189.

Donovan GP, Bjørge A (1995) Harbour porpoises in the North Atlantic: edited extract from the report of the IWC Scientific Committee, Dublin 1995. Reports of the International Whaling Commission, 16, 3-26.

Drummond AJ, Rambaut A (2007) BEAST: Bayesian evolutionary analysis by sampling trees. BMC Evolutionary Biology, 7, 214.

Drummond AJ, Rambaut A, Shapiro B, Pybus OG (2005) Bayesian coalescent inference of past population dynamics from molecular sequences. Molecular Biology and Evolution, 22, 1185-1192.

Estoup A, Jarne P, Cornuet J-M (2002) Homoplasy and mutation model at microsatellite loci and their consequences for population genetics analysis. Molecular Ecology, 11, 15911604.

Estoup A, Lombaert E, Marin J-M et al. (2012) Estimation of demo-genetic model probabilities with Approximate Bayesian Computation using linear discriminant analysis on summary statistics. Molecular Ecology Resources, 12, 846-855.

Falush D, Stephens M, Pritchard JK (2003) Inference of population structure using multilocus genotype data: linked loci and correlated allele frequencies. Genetics, 164, 1567-1587.

Fontaine MC, Baird SJE, Piry S et al. (2007) Rise of oceanographic barriers in continuous populations of a cetacean: the genetic structure of harbour porpoises in Old World waters. BMC Biology, 5, 30.

Fontaine MC, Tolley KA, Michaux JR et al. (2010) Genetic and historic evidence for climate-driven population fragmentation in a top cetacean predator: the harbour porpoises in Euro- 
pean water. Proceedings of the Royal Society of London B: Biological Sciences, 277, 2829-2837.

Fontaine MC, Snirc A, Frantzis A et al. (2012) History of expansion and anthropogenic collapse in a top marine predator of the Black Sea estimated from genetic data. Proceedings of the National Academy of Sciences, 109, E2569-E2576.

Foote AD, Vilstrup JT, De Stephanis R et al. (2011) Genetic differentiation among North Atlantic killer whale populations. Molecular Ecology, 20, 629-641.

Frantzis A, Gordon J, Hassidis G, Komnenou A (2001) The enigma of harbor porpoise presence in the Mediterranean Sea. Marine Mammal Science, 17, 937-944.

Fu YX, Li WH (1993) Statistical tests of neutrality of mutations. Genetics, 133, 693-709.

Gaskin DE (1984) The harbour porpoise Phocoena phocoena (L.): regional populations, status, and information on direct and indirect catches. Report of the International Whaling Commission, 34, 569-586.

Giosan L, Filip F, Constatinescu S (2009) Was the Black Sea catastrophically flooded in the early Holocene? Quaternary Science Reviews, 28, 1-6.

Goudet J (2001) FSTAT, a program to estimate and test gene diversities and fixation indices (version 2.9.3).

Grove JM (2004) Little Ice Age. Routledge, London, New York, New York.

Guindon S, Gascuel O (2003) A simple, fast, and accurate algorithm to estimate large phylogenies by maximum likelihood. Systematic Biology, 52, 696-704.

Hammond PS, Macleod K, Berggren P et al. (2013) Cetacean abundance and distribution in European Atlantic shelf waters to inform conservation and management. Biological Conservation, 164, 107-122.

Hartl DL, Clark AG (2007) Principles of Population Genetics. Sinauer Associates, Sunderland, Massachusetts.

Hasegawa M, Kishino H, Yano T (1985) Dating of the humanape splitting by a molecular clock of mitochondrial DNA. Journal of Molecular Evolution, 22, 160-174.

Hewitt G (2000) The genetic legacy of the Quaternary ice ages. Nature, 405, 907-913.

Ho SYW, Shapiro B (2011) Skyline-plot methods for estimating demographic history from nucleotide sequences. Molecular Ecology Resources, 11, 423-434.

Hoelzel AR (1998) Genetic structure of cetacean populations in sympatry, parapatry, and mixed assemblages: implications for conservation policy. Journal of Heredity, 89, 451-458.

Hubisz MJ, Falush D, Stephens M, Pritchard JK (2009) Inferring weak population structure with the assistance of sample group information. Molecular Ecology Resources, 9, 1322-1332.

Hudson RR (2000) A new statistic for detecting genetic differentiation. Genetics, 155, 2011-2014.

Hudson RR, Slatkin M, Maddison WP (1992) Estimation of levels of gene flow from DNA sequence data. Genetics, 132, 583-589.

Jimenez-Espejo FJ, Martinez-Ruiz F, Sakamoto T et al. (2007) Paleoenvironmental changes in the western Mediterranean since the last glacial maximum: high resolution multiproxy record from the Algero-Balearic basin. Palaeogeography, Palaeoclimatology, Palaeoecology, 246, 292-306.

Librado P, Rozas J (2009) DnaSP v5: a software for comprehensive analysis of DNA polymorphism data. Bioinformatics, 25, 1451-1452.
Lockyer C (2007) All creatures great and smaller: a study in cetacean life history energetics. Journal of the Marine Biological Association of the UK, 87, 1035.

Louis M, Viricel A, Lucas T et al. (2014) Habitat-driven population structure of bottlenose dolphins, Tursiops truncatus, in the North-East Atlantic. Molecular Ecology, 23, 857-874.

Major CO, Goldstein SL, Ryan WB et al. (2006) The co-evolution of Black Sea level and composition through the last deglaciation and its paleoclimatic significance. Quaternary Science Reviews, 25, 2031-2047.

Marx FG, Uhen MD (2010) Climate, critters, and cetaceans: Cenozoic drivers of the evolution of modern whales. Science, 327, 993-996.

Méndez-Fernandez P, Pierce GJ, Bustamante P et al. (2013) Ecological niche segregation among five toothed whale species off the NW Iberian Peninsula using ecological tracers as multi-approach. Marine Biology, 160, 2825-2840.

Moritz C (2002) Strategies to protect biological diversity and the evolutionary processes that sustain it. Systematic Biology, 51, 238-254.

Nabholz B, Glemin S, Galtier N (2007) Strong variations of mitochondrial mutation rate across mammals: the longevity hypothesis. Molecular Biology and Evolution, 25, 120-130.

Nei M, Li WH (1979) Mathematical model for studying genetic variation in terms of restriction endonucleases. Proceedings of the National Academy of Sciences, 76, 5269-5273.

Nosil P, Harmon LJ, Seehausen O (2009) Ecological explanations for (incomplete) speciation. Trends in Ecology \& Evolution, 24, 145-156.

Osborn TJ, Briffa KR (2006) The spatial extent of 20th-century warmth in the context of the past 1200 years. Science, 311, 841-844.

Palumbi SR (1994) Genetic divergence, reproductive isolation, and marine speciation. Annual Review of Ecology and Systematics, 25, 547-572.

Pastene LA, Goto M, Kanda N et al. (2007) Radiation and speciation of pelagic organisms during periods of global warming: the case of the common minke whale, Balaenoptera acutorostrata. Molecular Ecology, 16, 1481-1495.

Pierce GJ, Caldas M, Cedeira J et al. (2010) Trends in cetacean sightings along the Galician coast, north-west Spain, 20032007, and inferences about cetacean habitat preferences. Journal of the Marine Biological Association of the UK, 90, 15471560.

Pilot M, Dahlheim ME, Hoelzel AR (2010) Social cohesion among kin, gene flow without dispersal and the evolution of population genetic structure in the killer whale (Orcinus orca). Journal of Evolutionary Biology, 23, 20-31.

Pinela AM, Borrell A, Cardona L, Aguilar A (2010) Stable isotope analysis reveals habitat partitioning among marine mammals off the NW African coast and unique trophic niches for two globally threatened species. Marine Ecology Progress Series, 416, 295-306.

Pritchard JK, Stephens M, Donnelly P (2000) Inference of population structure using multilocus genotype data. Genetics, 155, 945-959.

Rambaut A (2007) Tracers v1.5. Available from http://tree.bio. ed.ac.uk/software/tracer/.

Roberts N, Brayshaw D, Kuzucuoglu C, Perez R, Sadori L (2011) The mid-Holocene climatic transition in the Mediterranean: causes and consequences. The Holocene, 21, 3-13. 
Rohling EJ, Abu-Zied R, Casford C, Hayes A, Hoogakker B (2009) The marine environment: present and past. In: The Physical Geography of the Mediterranean (ed. Woodward JC), pp. 33-67. Oxford University Press, Oxford.

Rosel PE, Dizon AE, Haygood MG (1995) Variability of the mitochondrial control region in populations of the harbour porpoise, Phocoena phocoena, on interoceanic and regional scales. Canadian Journal of Fisheries and Aquatic Sciences, 52, 1210-1219.

Rousset F (2008) genepop'007: a complete re-implementation of the genepop software for Windows and Linux. Molecular Ecology Resources, 8, 103-106.

Santos M, Pierce G (2003) The diet of harbour porpoise (Phocoena phocoena) in the northeast Atlantic. Oceanography and Marine Biology: An Annual Review, 41, 355-390.

Smeenk C, Leopold MF, Addink MJ (1992) Note on the harbour porpoise Phocoena phocoena in Mauritania, West Africa. Lutra, 35, 98-104.

Spitz J, Rousseau Y, Ridoux V (2006) Diet overlap between harbour porpoise and bottlenose dolphin: an argument in favour of interference competition for food? Estuarine, Coastal and Shelf Science, 70, 259-270.

Spötl C, Nicolussi K, Patzelt G, Boch R, Team D (2010) Humid climate during deposition of sapropel 1 in the Mediterranean Sea: assessing the influence on the Alps. Global and Planetary Change, 71, 242-248.

Szpiech ZA, Jakobsson M, Rosenberg NA (2008) ADZE: a rarefaction approach for counting alleles private to combinations of populations. Bioinformatics, 24, 2498-2504.

Tajima F (1983) Evolutionary relationship of DNA sequences in finite populations. Genetics, 105, 437-460.

Tolley KA, Rosel PE (2006) Population structure and historical demography of eastern North Atlantic harbour porpoises inferred through mtDNA sequences. Marine Ecology Progress Series, 327, 297.

Wakeley J (1994) Substitution-rate variation among sites and the estimation of transition bias. Molecular Biology and Evolution, 11, 436-442.

Watterson GA (1975) On the number of segregating sites in genetical models without recombination. Theoretical Population Biology, 7, 256-276.

Weir BS, Cockerham CC (1984) Estimating F-statistics for the analysis of population structure. Evolution, 38, 1358-1370.

Wiemann A, Andersen LW, Berggren P et al. (2010) Mitochondrial control region and microsatellite analyses on harbour porpoise (Phocoena phocoena) unravel population differentiation in the Baltic Sea and adjacent waters. Conservation Genetics, 11, 195-211.

Wiley EO (1988) Vicariance biogeography. Annual Review of Ecology and Systematics, 19, 513-542.

M.C.F. contributed to design research. M.C.F., K.R. and I.C. performed laboratory work. M.C.F. analysed data. F.A., K.A.T., J.R.M., M.F., T.J., A.L., B.O., A.A.O., V.R., E.R., M.S., U.S., G.A.V., A.B. and A.A. contributed sampling and analytic tools. M.C.F. wrote the manuscript with help from F.A., F.P.P., K.A.T., E.R., S.R. and A.A. and final approval by all co-authors.

\section{Data accessibility}

Data supporting this study are deposited at DRYAD (doi: 10.5061/dryad.k42dg).

\section{Supporting information}

Additional supporting information may be found in the online version of this article.

Appendix S1 Protocol for PCR amplification and sequencing of the five mitochondrial genes.

Appendix S2 Bayesian clustering population structure analysis using STRUCTURE.

Appendix S3 Supporting information details on the $A B C$ analysis.

Table S1 MtDNA genes analysed, primer used for PCR amplification, annealing temperature $\left(T_{\mathrm{a}}\right)$, and the length of the fragments sequenced obtained in this study.

Table S2 Lists of mitochondrial haplotypes carried by each individual sorted per population.

Table S3 Model specification, prior distributions for demographic parameters and locus-specific mutation model parameters.

Table S4 Nuclear microsatellite genetic diversity for each group.

Table S5 Microsatellite and mitochondrial divergence and differentiation between groups of harbor porpoises.

Table S6 ABC model selection procedure and performance analysis.

Table S7 Model checking procedure.

Table S8 Parameter estimation for scenario SC4 in natural units.

Table S9 Composite parameter for the scenario SC4 (see Fig. 2).

Fig. S1 Estimated number of populations from structue analyses and the LocPrior model.

Fig. S2 Estimated population structure by STRUCTURE using the standard admixture model and assuming 2-5 clusters $(K)$ (cf. legend Fig. 2).

Fig. S3 Estimated population structure by STRUCTURE using the Locprior admixture model and assuming 2-5 clusters $(K)$ (cf. legend Fig. 2). 